Nils Petter Hauan is a PhD - candidate in science centre pedagogic at the University of Bergen and senior developer at VilVite, Bergen Science Centre. His research interest focuses on science centres as educational resource for schools. He explores how interactive exhibitions can be utilized in curriculum based teaching

Stein Dankert Kolstø is professor in science education at the University of Bergen. His research interests focuses on use of dialogue and inquiry in science learning. In specific his interested in combining dialogic inquiry with the use of authentic texts related to socioscientific issues.

NILS PETTER HAUAN

University of Bergen, Norway

nph@vilvite.no

STEIN DANKERT KOLST $\varnothing$

University of Bergen, Norway

Stein.Dankert.Kolstoe@ift.uib.no

\title{
Exhibitions as learning environments: a review of empirical research on students' science learning at Natural History Museums, Science Museums and Science Centres
}

\begin{abstract}
One aim for many natural history museums, science museums and science centres is to contribute to school-related learning in science. In this article we review published empirical studies of this challenging area. The review indicates that the effectiveness of educational activities at different types of science-communication venues (SCV) in supporting students'science learning varies. There is also evidence of interesting differences between activities, depending on how these activities are designed. Firstly, these activities can stimulate interest and conceptual focus through a well-designed combination of structure and openness. Secondly, they can stimulate talks and explorations related to the presented topics. We have identified two possible areas which might prove fruitful in guiding further research: an exploration of the effects of different designs for guided exploratory learning, and an evaluation of the effectiveness of educational activities by studying the presence and quality of the learning processes visitors are engaged in.
\end{abstract}

\section{INTRODUCTION}

This review focuses on schools' utilization of exhibitions and educational activities at natural history museums, science museums and science centres (denoted for short as Science Communicating Venues or SCVs) and learning-related experiences provided by visits to such venues. Although we acknowledge that many types of learning outcomes are possible from visits to SCVs, in this review we focus on studies that include findings related to the facilitation of science-concept learning.

In the literature SCVs are often classified together with museums as institutions for informal learning (Hein, 2002). The use of the term informal serves to distinguish these institutions from schools, which are seen as institutions for formal or curricular learning. Rennie (2007) takes up the discussion 
regarding the words or labels formal and informal, and raises the question "Is there a difference?” (p. 126); she goes on to state that "it does not make sense to try to distinguish it as formal or informal." (p. 126). Rennie (2007) reminds us that processes of learning are not restricted to certain settings. Guided by the Contextual Model of Learning (CML) (Falk \& Dierking, 2000), we will take another approach to the discussion by looking into some factors of the CML which provide insight into how school visit differs from leisure-time visits such as family visits. Several researchers have argued that the SCV visit should support the classroom work (Bamberger \& Tal, 2007; Griffin \& Symington, 1997; Tal et al., 2005) and that the school curriculum should be used as a basic document for coordinating the activities in these educational arenas (DeWitt \& Storksdieck, 2008; Griffin, 2004). The agenda of supporting classroom curricular-based work is linked to both the factors "Motivations and expectations" and "Choice and control" in the CML (Falk \& Dierking, 2000 p. 137). This agenda is expressed by most teachers as their main goal with a visit (Anderson \& Zhang, 2003; Griffin \& Symington, 1997; Kisiel, 2005). Other CML factors are "Within-group sociocultural mediation" and "Facilitated mediation by others" (Falk \& Dierking, 2000 p. 137). The mediation within a small group such as a family (Ash, 2003; Rosenthal \& Blankman-Hetrick, 2002) differs from the mediation during a school trip where there are many students, few teachers and occasionally no designated staff. The nature of the school visits is shaped by teachers' agendas and the characteristics of mediation during the school visit. We have therefore chosen to only include studies of school visits in this review.

Several reviews of this field have been published. One is the previously referred to book by Falk and Dierking (2000), in which they present, based on writings within the rich fields of museums and learning, a model that describes how learning is contextualised and identifies key factors which influences in the quality of the museum experience. Another contribution is the article by Pedretti (2002), which takes up the discussion of why and how science centres and science museums should present socioscientific issues. One of the reviews which deal more specifically with relations between schools and other learning arenas is the previously mentioned article by Rennie (2007), which is a seminal review of literature within the wide area of learning "outside of school". It discusses major issues within this field and contributes to the discussion by stating: "[...] the value of learning outside of school should be recognized and its benefits harnessed to complement our formal educational programs" (p. 156). In a review of literature on school field trips to "out of school" settings, DeWitt and Storksdieck (2008) state that field trips such as visits to SCVs can be a valuable resource if they are incorporated into classroom teaching, and go on to discuss the influence which the personal, social and physical contexts, teachers' agendas and the quality of pre- and post-visit material has on the outcomes of the visit. A main claim in their review is that it is necessary to include pre- and post-visit activities at school, and to provide activities which facilitate students' efforts to link visit-generated primary experiences to classroom work. They also report that teachers' agendas have a great influence on how the exhibition is utilized and thereby on the educational outcome.

In the present review, based on empirical findings and supported by learning theory, we focus on how SCVs' exhibitions can be utilized as a learning environment, examining the possible roles of structuring and openness (e.g. no choice versus free choice), and the possible contribution of different activities at SCVs in which the students investigate and talk about science-related topics. The discussion also considers the impact of how the experience is structured, as well as how the given tasks can lead to cognitive activities, thus supporting the processes of learning.

\section{METHOD}

The objective of the literature search was to identify empirical studies of school classes' visits SCV exhibitions, with a focus (partly or solely) on students' concept learning in science. However, in order to encompass the maximum number of articles, we have not applied criteria for methodologies used. Thus, we have included findings based on end of visit tests, teachers' impressions, student interviews, analyses of student assignments, questionnaires, concept-maps, and personal-mind-maps, in 
addition to studies documenting activities and processes believed to characterise productive learning processes. The literature search was initiated using the ISI Web of Knowledge, applying the key words "learning, science, museum", setting the timespan from 1945 until the end of 2012, with "Education Educational Research" as category and "Article" as document type. The initial number of articles found by ISI was 112; this was reduced to 55 after excluding 25 articles not related to SCVs and 32 articles not related to schools. An investigation of the residual articles revealed that some significant relevant works published in international journals were not listed. The search was therefore expanded by conducting an equivalent search in the databases of the journals Teaching Education and Visitor Studies, and by utilizing Google Scholar to search for articles in the International Journal of Computer-Supported Collaborative Learning, the Journal of Science Teacher Education, the Journal of Computer Assisted Learning, Research in Science Education, Systems and Computers in Japan, and Visitor Studies Today. The initial number of 57 new articles found by this expanded search was reduced to 25 by excluding 24 that were not related to SCVs and 8 not related to schools. These searches resulted in a total of 80 articles. On the basis of the topic for the review, we then excluded 20 non-empirical articles, 2 articles not focusing on science-concept learning, 3 about workshops, 2 about gender issues, 5 about live animal exhibitions, 3 about planetarium shows, 3 about the use of internet unrelated to the SCVs' exhibitions and 4 about organizing partnership. These exclusions resulted in a set of 38 articles.

The analysis of the identified research studies proceeded in several steps. For each paper, a summary was made focusing on the following elements: research questions and topic, the structure of the visit or how the visit was characterised, student's age, data collection and methods of analysis, main findings and main claims, and conclusions in the discussion. When several topics and research questions were dealt with in a study, the paper was entered under each relevant topic in a data matrix (Miles \& Huberman, 1994) using MS-Excel. All elements in the summaries were entered into the data matrix to provide an overview and facilitate identification of common topics. In the review by DeWitt and Storksdieck (2008), the effects of pre- and post-visit activities are thoroughly discussed. Thus, 9 studies on these subjects were excluded since they did not change the conclusions reached by this previous review. Focusing on the facilitation of student engagement in science learning during visits, two main categories (and several subcategories for facilitating devises) were identified: findings regarding how to facilitate learning at exhibitions and findings regarding how to organise student visits. The associated 29 articles are categorized in table 1.

In interpreting the results in this review, we believe there are two main concerns one needs to be aware of. Firstly, most of the patterns identified are based on relatively few studies. This implies that all results have to be viewed as hypotheses for further research, and as working hypotheses (Cronbach, 1975) for practitioners at SCV. Secondly, although we are well aware that conceptual understanding normally takes time and effort to develop, we set out to identify findings on students' science learning from SCV-visits. However, few studies have really tried to measure students' science learning. Many studies have been limited to collecting various actors' views on students' learning outcomes, and many studies use general phrases like educational value, etc. which need to be more clearly defined. Vague terminology sometimes makes it hard to compare studies and different types of facilitation for learning.

\section{STRUCTURING VISITS}

In this section we will examine studies exploring the effects of various forms and levels of structuring in visits to SCVs, exhibitions.

\section{The influence of Structure the Learning Situation}

In a seminal study, Bamberger and Tal (2007) identified three different categories of choice with different consequences for students' actions and learning based on observations and interviews with 
Table 1. Articles reviewed and corresponding categories and sub-categories in the review.

Structuring the visit

Influence of Structuring the Learning Situation

Bamberger \& Tal, 2008, b; Bamberger \& Tal, 2007; Cox-Petersen, Marsh, Kisiel

\& Melber, 2003; DeWitt \& Hohenstein, 2010; DeWitt \& Hohenstein 2010, b;

Griffin, 1994; Griffin \& Symington, 1997; Jarvis \& Pell, 2005

Facilitating learning in exhibitions

Characteristics of exhibit design affecting students' learning

Anderson \& Lucas, 1997; Anderson, Lucas, Ginns \& Dierking, 2000; Bamberg-

er \& Tal, 2008; DeWitt \& Osborne, 2010; Falcão et al., 2004; Gilbert \& Priest, 1997; Henriksen \& Jorde, 2001;Rix \& McSorley, 1999; Yoon, Elinich, Wang,

Steinmeier, \& Tucker, 2012

Design and effects of worksheets

Griffin \& Symington, 1997; Kisiel, 2003; Kisiel, 2007; Mortensen \& Smart, 2007; Stavrova \& Urhahne, 2010; Rix \& McSorley, 1999

The Use of Narratives

Henriksen \& Jorde, 2001; Metz, 2005

The Use of Technology

DeWitt \& Osborne, 2007; Heard, Divall \& Johnson, 2000; Hsi, 2003; Hwang,

Tsai, Chu, Kinshuk \& Chen, 2012; Yatani, Onuma, Sugimoto \& Kusunoki, 2004

\section{Guiding by SCV Staff}

Bamberger \& Tal, 2007; Cox-Petersen et al., 2003; Stavrova \& Urhahne, 2010;

Tal, Bamberger \& Morag, 2005; Tal \& Morag, 2007

10-15 year old students on SCV visits. The first category was no choice, which was categorized by strict exhibition guiding, a finding consistent with previous findings by Cox-Petersen et al. (2003). In this visit category, Bamberger and Tal (2007) found that few attempts were made to link the visit to the curriculum or to connect the discussed concepts to the students' previous knowledge or experience. It was concluded that the students' curiosity and eagerness to explore were suppressed. In visits categorised as limited choice, students first received an introduction and were then given various kinds of assignments. These assignments engaged the students in content-related talks. More studentteacher and student-guide interactions were observed compared with the no-choice visits. Students made connections on their own to school and non-school related knowledge. It was found that some freedom of choice, combined with exhibition guiding, active teachers and prepared material for the assignments, supported the students in their learning process. However, some students experienced challenges in finishing the tasks. Finally, in visits categorised as free choice, the students were free to explore the exhibition as they wished. The students were exited and socialised with their friends, but there was little observed content-related talk. In addition, some students did not see the purpose of interacting with the exhibits and this led to frustration.

Bamberger and Tal (2008, b) investigated the long term effect of a visit to a science museum by 13-16-year-old students, in which the structure combined a guide-directed tour of three exhibitions with free exploration of the same exhibitions. Interviews conducted the day after the visit indicated that most of the students connected the content of the exhibition with their prior school knowledge, 
and about one third of the students referred to such connections 16 months later. All of the students, whenever interviewed, felt that they had learned by cooperating with peers. Such findings support the view that an intermediate degree of structure has the potential to support social learning.

DeWitt and Hohenstein $(2010 ; 2010$, b) conducted observational investigations of school visits to two science museums. The visits were characterized by an open structure in which the 9-12-year-old students selected the topics before the visit, gathered information related to the topics during the visit, and used this material after the visit. The analysis of data from audio recordings and observations of the students indicated that the visits resulted in more balanced discourses between teacher and students, and that students took a more proactive role during the visit than in the classroom (DeWitt \& Hohenstein, 2010). The students were more cognitive and affectively engaged during the visit than they were in the classroom, and content-related talk were more frequent (DeWitt \& Hohenstein 2010, b).

By analysing worksheets, conducting interviews and observing 10-16-year-old students and their teachers in connection with visits to two venues in Sydney (Griffin, 1994; Griffin \& Symington, 1997), it was found that differences in agendas (learning oriented, task oriented or neither) and types of student tasks influenced the structure of visits. Interviews with students during and after the visits revealed that the students had clear preferences regarding the structure of the visits; they wanted to be able to influence the execution of the visit, to be sure that the educational activities supported their school work and to work in groups (Griffin \& Symington, 1997).

In a qualitative investigation of visits to the UK Space Centre, Jarvis and Pell (2005) found that providing structure via a combination of focused and manageable tasks and of facilitative support by adults was a successful strategy for creating interest and reducing anxiety about science. This indicates that young students can benefit from adult guidance to help them to choose from the wide range of offered experiences.

With regard to students' reactions to different types of structuring, the studies reviewed indicate the following: A no-choice structure might ensure a focus on predefined concepts and activities but suppress eagerness to explore, and might not lead to content-related talk; free choice might stimulate excitement, but little content related talk, and can result in frustration. Limited choice can reduce anxiety, and stimulate interest and student-teacher interactions although it may generate challenges in ensuring progress in the completion the educational tasks (Bamberger \& Tal, 2007). On the other hand, appropriately designed tasks (including worksheets) can increase such progress. Limitedchoice structuring involving opportunities for self-governed exploration and cooperation also seem to encourage content-related talk among students with the potential to enhance the learning outcomes of the visit (Bamberger \& Tal, 2007; DeWitt \& Hohenstein, 2010, b).

\section{FACILITATING LEARNING IN EXHIBITIONS}

An SCV consists of exhibits typically designed as standalone units and designed to communicate one or several science-related topics. The core purpose of the exhibits and the venue as a whole is, apart from stimulating interest, to support learning (Falk \& Dierking, 2000; Lord, 2001). Moreover, the findings presented in DeWitt and Storksdieck's (2008) review indicates that this purpose is reflected in many teachers' beliefs and agendas for SCV visits. In this section, we will consider findings from studies that have explored exhibits as learning material, as well as the methods used to support the intended learning outcome of a single exhibit or the intended learning outcomes of several exhibits grouped together within a theme.

\section{Characteristics of exhibit design affecting students' learning}

A key element which can affect students' learning from a SCV visit is the design of the exhibits themselves. 
In a study using concept maps and interviews of 11-12-year-old students, Anderson et al. (2000) found that the conceptual understandings the students developed from interacting with an exhibit were dependent on how the phenomena were presented in the design and by the labels; and that the students' interpretations of their observations were influenced by their previous experiences. For instance, an exhibit that was designed to illustrate how magnetism is changed by extreme heat was misinterpreted and resulted in misunderstandings related to how magnets work.

Similarly, Henriksen \& Jorde (2001) found that complex exhibits designed to communicate the topic of radiation and health were often misunderstood by high school students; and that the students did not always utilize the information provided the way the designer had intended.

Falcão et al. (2004) interviewed 9-16-year-old students to determine their understanding of the complex relation between the sun, the moon and the earth after they had visited an exhibition on that topic. They concluded that the student's conceptual understanding of complex topics was optimized by combining exhibits presenting composite phenomena with exhibits focusing on only one phenomenon.

By analysing students' answers to post-test questionnaires, Anderson and Lucas (1997) identified some design properties that influenced the potential of the exhibit as educational material. They found that physically large, interactive exhibits that are highlighted in the exhibition are more often discovered, used and recalled by the 13-14-year-old students, and are therefore more likely to support learning. In addition, in a qualitative study Gilbert and Priest (1997) found that the ability of 8-9-yearold students to recognize an exhibit as being familiar was critical in initiating a discussion with fellow visitors on a related topic. For this discourse to continue, it was essential that the exhibit somehow enabled the visitors to identify some links to their everyday lives.

Rix and McSorley (1999) investigated young children interacting with exhibits in a small school-based museum. They found that, although young children often seemed to be playing randomly with exhibits, the exhibits with changeable elements were utilised for systematic exploration. Many students also used scientific terms and expressions, and some tried to explain their observations in such terms. They concluded that, although the exhibits were not necessarily used as intended by the designers, the children's playful exploration could be characterized as scientific work. These finding are echoed by DeWitt and Osborne (2010), who found that many science-centre exhibits generated playful exploration. They also revealed several significant exhibit design factors for engaging the 9-11-year-old students: hands-on interaction, multiple opportunities for exploration and collaboration, and phenomena that contrasted with previous experiences or that were perceived as cognitively challenging. Based on their findings from observations of students during museum visits and semi-structured follow-up interviews, Bamberger and Tal (2008) add the design principle that exhibits should be designed to facilitate discussions.

A study by Yoon et al. (2012) investigated the effect of adding digital visualisation and directed questions to an existing exhibit as design elements. Observations and interviews with 12-14-year-old students did not reveal significant changes in conceptual learning gains; however, there were indications of increased skill in theorizing about the phenomenon.

These studies indicate that certain characteristics of an exhibit, such as size, interactivity, supporting visualisations, questions and possible links to everyday life, may increase visitors' use, discussions, theorizing, recall and probably also science-concept learning. Moreover, exhibits enabling interaction may lead to unintended use involving playful exploration and hypothesis testing resulting in attempts to explain using scientific terms. Another important finding was that students' interaction with exhibits can generate other but accepted cognitive understandings (Anderson et al. 2000; Henriksen \& Jorde, 2001, Rix \& McSorley, 1999). There are also indications that exhibits that are complex and 
dependent on the users having sufficient background knowledge can be misunderstood more easily, risking alternative conceptual understandings. The findings by Falcão et al. (2004) indicate that the challenge of complexity can be overcome by designing a cluster of exhibits that present different elements of the subject matter. Nevertheless, studies on the influence of design on students' learning are few, and need to be interpreted with care.

\section{Design and effects of worksheets}

Although some research has found that worksheets utilized in an SCV can lead to a narrowing of focus towards 'finding the right answer' and that students often consider worksheets dull (Griffin \& Symington, 1997; Rix \& McSorley, 1999), more recent research has emphasised that the type of worksheet matters.

Kisiel (2003) interviewed teachers who have developed such worksheets. He found that they viewed worksheets as critical for keeping students focused and for leading them through the planned educational activities. He also identified two main agendas underpinning the design of worksheets. Worksheets based on a survey agenda were intended to provide students with an overview of much of the museum and involved activities such as collecting facts, reading and copying text from exhibition labels. Those based on a concept agenda were consistent with a particular conceptual learning goal and placed greater emphasis on observations rather than label reading. However, concept-agenda worksheets typically had little information regarding where the answers could be found, which was confusing and distracting for some students.

In another study, Mortensen and Smart (2007) investigated the use of Chaperone's Guides, a type of worksheet designed to facilitate group dialogue. These were developed in an attempt to encourage some free-choice learning while meeting teachers' requirements for content connected to the curriculum. Observations and analysis of conversations that occurred during the visit indicated that the guides increased the conversations related to the intended curricular learning outcome. However, while some of the 8-11-year-old students preferred the open ended questions that allowed for different ways of approaching the subject, others were frustrated by the same tasks and preferred closed questions with only one correct answer.

In another study, Stavrova \& Urhahne (2010) investigated a redesign of an educational activity at the Deutsches Museum. The redesign involved, among other elements, changes to worksheets, in which the open questions of the previous worksheets were replaced by multiple-choice questions in which the right answers led to a solution word. The studied 13-16-year-old students were given points for the right solution words and a winner was declared. Findings suggest that the redesign of the worksheets had a positive influence on the students' attitudes and understanding of topics covered in exhibitions.

In a study, Kisiel (2007) asked teachers to examine one survey agenda worksheet and one concept agenda worksheet designed for a trip to a natural history museum. $60 \%$ of the teachers preferred a survey agenda for a visit with 4 th and 5 th grade students, while $70 \%$ preferred it for 7 th and 8 th grade students. Some of the most significant rationales given by the teachers for their choice were high task density, directedness, level of difficulty, relevance, question format and cognitive level. None of the teachers gave curriculum connection as the rationale for their choice. Moreover, there were some cases of lack of coherence in teachers' preferences; for example, while some teachers chose the survey agenda type because of its high task density, others rejected this type for the same reason. Only one correlation was found to be consistent: teachers who focused on task relevance for the students preferred the concept-oriented worksheets. They stated that this type was more enjoyable and provided a more meaningful learning experience. 
Findings related to the possible role of worksheets in stimulating and facilitating learning depict a complex picture. Mortensen \& Smart (2007) have documented how worksheets can be designed so that the rate of curriculum-related group dialogues increases, thus potentially supporting learning. However, worksheets with other characteristics can result in an emphasis on completion and reduced focus on learning, and some students consider worksheets boring (e.g. Griffin \& Symington, 1997).

\section{The Use of Narratives}

Henriksen \& Jorde (2001) presented students with a narrative in the form of a "real life" story which was designed to serve as a common thread through the SCV visit phases: the preparation, the visit to a technical museum and the post-visit reflection. Based on a comparison of pre- and post-texts, the researchers concluded that the high school students' written language became less personal and more scientific.

To investigate narratives as a way to create a stimulating context for SCV experiences and support learning from them, Metz (2005) studied a teacher-student programme at a historical museum where science was conveyed by using role-play and historical exhibits as props in a story about how the exhibited objects were used. They found that students' preparation for and participation in a performance served as an engaging learning activity.

Although only two articles were found on the use of narratives and their influence on learning, the findings indicate that narrative is a promising instrument for facilitating engagement and science learning. A common characteristic of these two studies seems to be the use of narratives to help students stay focused, while at the same time allowing for personal choices and actions within the narrative frame. Some non-empirical studies have argued the need to explore the use of narratives further. Rounds (2002) views narratives as a means to elucidate the relationship between science and society. Bedford (2001) adds that the use of narratives coincides with everyday learning and that this probably implies that remembering is facilitated.

\section{The Use of Technology}

Technology has often been advocated as a way of supporting learning from SCV visits.

In one study, Heard et al. (2000) investigated the utilization of audio-guides as a tool to increase the learning of 9-11-year-old students from exhibit interaction. The auditory commentary led the user through different experiments and described generally expected results. Questionnaires measuring knowledge of pendulums reflected that girls improved their knowledge by roughly $100 \%$ and boys $25 \%$ when they used the audio guides. Corresponding values for the control group, however, were a $5 \%$ increase among girls but 50\% among boys.

In a study by Hsi (2003), users were equipped with PDAs, including an ear-plug, which provided additional information about exhibits, suggestions for interactions and explanations to phenomena. The system also recorded the students' experiences on a personalized web site for later recapture and reflection. Most of the users liked the system and it seemed to encourage new ways of playing with the exhibits. However, some users, including teachers, reported a negative impact in that it created a feeling of isolation from social interaction and restricted explorative behaviour.

In another study, Yatani et al. (2004) conducted research on the utilization of a computer-based network system and PDAs to present multiple-choice questionnaires to users. Answers to the questions could be found by interacting with the exhibits and by reading the explanatory texts. They found that $94 \%$ of visiting 6-12-year-old students enjoyed using the system and $84 \%$ believed that it facilitated their learning. It was also found that the intended increase in attention compared to less used exhibits was achieved. 
In a more straightforward use of technology, students visiting a science museum were asked to take photographs, write notes and use this as material for generating a post-visit presentation. Data analyses of the behaviours of observed 9-10-year-old student indicates that the post-visit presentation assignment fostered cognitive engagement during the visit and fruitful discussions during the post-visit production (DeWitt \& Osborne, 2007).

In their study, Hwang et al. (2012) compared the learning outcome for 10-11-year-old students who completed PDA-guided inquiry-based tasks linked to exhibits, with those of students who completed similar task that were teacher-guided. The post-tests showed highest achievement scores for those students who were lead through the processes of scientific inquiry by the user controlled instructions incorporated in the PDA.

The reported findings indicate that the use of PDAs and multimedia phones has the potential to increase the time spent on exhibitions, to support students' conceptual learning and to make exhibitions more memorable. However, there are also indications that PDA's can restrict visitors' exploration. The study by Hwang et al. (2012) indicates that technology can be used in educational activities designed to increase students' explorative behaviour.

\section{Guiding by SCV Staff}

Many SCVs employ staff to facilitate or scaffold students' learning from SCV visits.

Observations of guided tours at a natural history museum lead Cox-Petersen et al. (2003) to conclude that guiding at the different exhibitions mainly followed a prepared script that was not adjusted to students' previous knowledge and focused on facts rather than ideas or concepts. Moreover, most guides relied mainly upon closed questions to stimulate interaction. Measured learning outcomes detected few cases of conceptual learning. Most of the teachers and the 7-14-year-old students expressed their appreciation of the guided tours and considered them to be a fruitful learning experience. However, about half of the teachers suggested that the guiding should be less structured and more specifically linked to students' previous knowledge and interests.

In order to investigate the teachers' role and perceptions related to SCV visits, Tal et al. (2005) studied educational activities offered by four natural history museums in Israel. These activities utilised various methods of dissemination, such as instructional talks, tours in the exhibition, demonstrations, games, and worksheets. Most of the teachers approved of the methods used by the guides to support learning. However, they also expressed their concerns about too much lecturing, irrelevant movies, too few links to the students' previous knowledge and too little time for free-choice investigation (Tal et al., 2005).

In their analysis of observations and interviews with students from primary, middle and high school students in connection with visits to science and national history museums, Bamberger and Tal (2007), and Tal and Morag (2007) found similar issues when the educational activities were tightly controlled by a guide. On such guided tours, there were very few attempts to connect the content to the students' previous knowledge or interests. Tal and Morag (2007) found very few attempts to challenge the students to express their own thoughts. Bamberger and Tal (2007) argue that tightly controlled activities may suppress students' motivation for further exploration.

The effects of redesigning a guided visit were investigated by Stavrova and Urhahne (2010) in a mixed-method qualitative and quantitative study. The guided tour in a new energy exhibition was changed so that the dominant unidirectional communication was replaced by dialogical communication between the staff and the 13-16-year-old students. The guides presented questions and some alternative answers to these; they then commented on each student group's choice of answer. The findings indicate that this modification meant that the students were less bored and more motivated. 
The above-mentioned findings (Bamberger \& Tal, 2007; Cox-Petersen et al., 2003; Stavrova \& Urhahne, 2010; Tal et al., 2005; Tal \& Morag, 2007) suggest that communication by staff can be unidirectional and involve closed questions, and that few attempts were made to link or adjust the material to suit students' previous knowledge or interests. The structure of some of the studied visits also offered few opportunities for free-choice exploration and were not flexible in terms of adjusting to requests and inputs from students. Moreover, the learning outcome was often found to be rather low, and facts were usually in focus rather than ideas.

However, the findings of Stavrova and Urhahne (2010) show the possibility of shifting from monologues towards more dialogue-oriented communication. Thus, the question does not seem to be whether or not guided tours support learning, but how guided tours might be designed to increase students' engagement and learning.

\section{Discussion}

This review suggests that the effectiveness of SCV educational activities in supporting students' science learning is variable. However, interesting differences between activities have been revealed, and these differences are not between the use of worksheets, narratives, PDA-technology or staff, but rather between the ways such resources are designed and used. We have identified two possible areas for research which may prove fruitful in taking research on science learning in SCV a step further: The effects of different designs on guided exploratory learning; and the evaluation of the effectiveness of educational activities, designs and activities by studying the presence and quality of the learning processes the visitors are engaged in.

\section{Level of structuring}

Utilizing SCV exhibitions for curricular learning implies guiding students towards specific educational goals determined by the teacher or SCV-staff, not by the student. Such guidance - whether it is achieved through the use of worksheets, PDAs, narratives or SCV staff - implies challenging the view that an exhibition as an arena for free-choice learning (Falk \& Dierking, 2000 p.xii). However, if curriculum-related science learning is taken as an aim, the question becomes how learning can be supported within a context that involves students' use of SCV-exhibits. In their study of structure, Bamberger and Tal (2007) found that students enjoy free exploration of an exhibition. However, they also found that free exploration can create frustration and, more importantly, that this lack of structure generated little learning-related behaviour. Other research suggests that appropriate structure and guidance can lead to increases in interest (Jarvis \& Pell, 2005), as also previously found by Rennie (1994). Finally, visits that are too strictly controlled can be counterproductive for learning, by restricting students' learning-related behaviour (Bamberger \& Tal, 2007; Griffin \& Symington, 1997; Heard et al., 2000; Hsi, 2003; Kisiel, 2007; Rix \& McSorley, 1999).

One possible interpretation of these findings is that SCV educational activities should provide both freedom of choice and structure to facilitate both personal motivation and focus on relevant activities, observations and concepts. The need for structure and rules to provide focus is also supported by Csikszentmihalyi and Hermanson (1995), who claims that educational activities that facilitate curiosity and interest are characterized by having "clear goals and appropriate rules" (p.36). Dewey (1938) adds to this perspective by reminding us that "without rules there is no game" (p.52) - and games allow for exploration and playful action. This indicates that the apparent conflict between guidance and free choice, and the need to balance these, may have an alternative solution. Similarly, we believe that evidence from research on structure indicates that SCV visits can be designed to provide both freedom of choice and structure. We believe that this idea, which may be denoted as guided exploratory learning, is congruent with the view held by Bamberger and Tal (2007), who concluded that "activities in museums that allow controlled choice are most suitable” (Bamberger \& Tal, 2007). 
One example of how this might be practically implemented involves the use of worksheets, which are generally regarded by teachers as appropriate tools for structuring a visit (Kisiel, 2003). It has been found that worksheets with closed tasks can reduce students' motivation (Griffin \& Symington, 1997), restrict exploratory behaviour (Rix \& McSorley, 1999) or focus students' attention primarily to the label text of the exhibits (Kisiel, 2003). However, worksheets with open-ended tasks have been found to generate open discussions and are preferred by some students (Mortensen \& Smart, 2007). Such worksheets are also considered by some teachers to be more enjoyable for the students and to generate more meaningful learning experiences than worksheets with closed tasks (Kisiel, 2007). These findings indicate that worksheets with open questions can facilitate some degree of free-choice exploration, yet within boundaries. How to design worksheets that provide for both freedom of exploration and necessary guidance should continue to be an area for further research.

Bamberger and Tal's (2007) categories free, limited and open choice denoting levels of structure seem to be valid and useful for the analysis of visits. Kisiel (2003) and Griffin \& Symington (1997) add to this categorisation when they find that design of worksheets for different purposes for example, to stimulate students to survey the SCV, to complete tasks or to focus on specific scientific concepts impose different categories of visit structures.

Studies by Griffin and Symington (1997), Mortensen and Smart (2007) and Cox-Petersen et al. (2003) send a mixed message about teachers' and students' preferences for different levels of structuring. Some teachers and students prefer that students have considerable choice in determining how the visit will proceed, while others prefer greater structure and curriculum relevance. One might hypothesise that the various preferences may be due to different views about teaching and learning, and different anticipated outcomes of the visit.

The use of narratives reported by Metz (2005) implies using a narrative and an open-ended task to guide exploratory learning. While the task demands structured preparation for a performance within the boundaries of the given context, it also involves playful activities within "the rules of the game".

PDAs and other transportable ICT-equipment could also be used in guided exploratory learning since they allow for some free choice by enabling the students to control the guidance provided by the equipment (Heard et al., 2000) or to expand the degree of freedom by pointing to more ways of using an exhibit (Hsi, 2003). However, findings indicate that audio-based technology can restrict exploratory behaviour (Heard et al., 2000; His, 2003), and social interaction (His, 2003). The multi-modality of PDAs and multimedia-phones provide a wide range of features which paper-based worksheets do not have, and research regarding how to utilize these features in order to provide students with both structure and openness in the visit seems to be desirable.

\section{Facilitating explorative processes important for science-concept learning}

The studies reviewed in this paper have made use of a range of methods for gathering information on students' learning. In particular, learning has been identified by analysing observations of students during visits to SCVs, concept maps and written texts produced by students, students' responses on questionnaires and in interviews, and students' and teachers' opinions regarding students' learning. The documented effects of these visits on students' learning vary, often being less than hoped for. However, this should not come as a surprise. Concept learning normally take time, and to measure changes in conceptual understanding after a few hours of exhibition guiding, task completion and playful interaction seems both demanding and inappropriate (Allen, 2002; Dierking, Falk, Rennie, Anderson \& Ellenbogen, 2003). An example of these difficulties is the documented development of new alternative concepts among some students during SCV visits. Such development or reinforcement of misconceptions is also found in studies involving leisure-time visitors to SCVs (e.g. Stocklmayer \& Gilbert, 2002). This challenge is in accordance with Novak's (2002) review of research on concept 
learning, in which he shows how weak prior knowledge can result in increases in misconceptions. One way to combat this development is to include pre- and post- visit activities. However, if changes in understanding are measured across the whole learning period, it is difficult to isolate the contribution of SCV visits to students' learning, compared with the contribution of pre- and post-visit activity. Nevertheless, if we agree that the ideal is to include pre- and post-visit activities (DeWitt \& Storksdieck, 2008), this discussion about possible sources of effects becomes less relevant.

Another approach, which we suggest, is to focus on explorative processes believed to be fruitful for learning. Today, it is widely acknowledged that conceptual learning in science is dependent on the student's active mental and verbal involvement, and to the linking of concepts to observations, experiences and prior knowledge (e.g. Ausubel, Novak \& Hanesian 1978). Concept learning involves the exploration and identification of possibly relevant prior knowledge, in order to provide anchor points for new ideas and prepare for restructuring (Novak, 2002). However, it also involves the active exploration of experiments and observations, the generation and exploration of possible interpretations of observations and the exploration of possible ways to understand and talk about experiences and observations using everyday language and science concepts. These explorative processes are fuelled by the inputs and guidance of more knowledgeable supervisors (Vygotsky, 1986) or texts (Coxall, 1994) All these explorative processes involve the learner's active use of language, whether inner speech or oral and written discussion (Vygotsky, 1986). For some individuals, learning based on reading, quiet observation and inner dialogic speech is fruitful, while for others this approach is overly taxing and counterproductive (Dunn, 1984; Gardner, 2006). One possibility, therefore, is to study the presence and quality of different explorative processes involving practical experiences, testing and observation and explorative conversations and writing during SCV visits with different types of educational activities. This process perspective may facilitate the documentation of fruitful learning processes that are going on at SCVs, even when high scores on tests on concept learning are irrelevant or hard to achieve.

The present review indicates that this approach to researching school trips can be workable and fruitful since several studies have shown how certain ways of designing the roles of staff or teachers may result in dialogic communication with students (Bamberger and Tal, 2007; DeWitt and Hohenstein, 2010, a; DeWitt and Hohenstein, 2010, b; Stavrova and Urhahne, 2010). Some studies have documented how it is possible to engage students in content-related talk, and how this may have been triggered by the familiarity of the topic of an exhibit (Gilbert \& Priest, 1997), stimuli in a worksheet (Mortensen \& Smart, 2007), interesting observations at exhibits (DeWitt \& Osborne, 2010; Rix \& McSorley, 1999) and pair work towards a common goal (DeWitt and Hohenstein, 2010, b). Moreover, Bamberger and Tal (2008) found that students felt that cooperating with peers contributed to their learning. Other studies have shown that wisely designed exhibits support students' learning (Anderson \& Lucas, 1997; Gilbert \& Priest, 1997) and trigger testing of hypotheses (Rix \& McSorley, 1999). In addition, the relevance of reading labels (Yatani et al., 2004) and recording findings on worksheets (DeWitt \& Osborne, 2007) have been documented in situations characterised by elements of choice within a focused but motivating structure. On the other hand, the review also presents a range of studies which indicate that not all uses of worksheets, PDAs and staff lead to the desired amount of participation, exploration, content-related conversations and label reading (e.g. Cox-Petersen et al., 2003; Griffin \& Symington, 1997; His, 2003). However, in these studies it seems less clear which characteristics of the physical exploration process can be regarded as relevant for concept development. Further research regarding the quality of different types of physical exploration in relation to science concept learning seems needed here.

Future research with a conscious and explicit focus on the presence and quality of relevant explorative processes may make it possible to better judge the learning potential of the SCV-visit. This view is supported by Rennie, Feher, Dierking \& Falk (2003), by stating that "learning is both a process and a product so we need to investigate the processes of learning as well as the products" (p.116). 


\section{REFERENCE}

Allen, S. (2002). Looking for learning in visitor talk: A methodological exploration. Learning Conversations In Museums. In K. Crowley, K. Knutson \& G. Leinhardt (Eds.), Learning conversations in museums (pp. XIII, 461 s.). Mahwah, N.J.: Lawrence Erlbaum.

Anderson, D., Lucas, K. B., Ginns, I. S., \& Dierking, L. D. (2000). Development of knowledge about electricity and magnetism during a visit to a science museum and related post-visit activities. Science Education, 84(5), 658-679.

Anderson, D., \& Lucas, K. L. (1997). The Effectiveness of Orienting Students to the Physical Features of a Science Museum Prior to Visitation. Research in Science Education, 27(4), 485-495.

Anderson, D., \& Zhang, Z. (2003). Teacher Perceptions of Field-Trip Planning and Implementation. Visitor Studies Today, 6(3), 6-11.

Ash, D. (2003). Dialogic inquiry in life science conversations of family groups in a museum. Journal of Research in Science Teaching, 4O(2), 138-162.

Ausubel, D. P., Novak, J. D., \& Hanesian, H. (1978). Educational psychology: a cognitive view (2d ed.). New York: Holt, Rinehart and Winston.

Bamberger, Y., \& Tal, T. (2007). Learning in a personal context: Levels of choice in a free choice learning environment in science and natural history museums. Science Education, 91(1), 75-95.

Bamberger, Y., \& Tal, T. (2008). Multiple Outcomes of Class Visits to Natural History Museums: The Students' View. Journal of Science Education and Technology, 17(3), 274-284.

Bamberger, Y., \& Tal, T. (2008, b). An Experience for the Lifelong Journey: The Long-Term Effect of a Class Visit to a Science Center. Visitor Studies.

Bedford, L. (2001). Storytelling: The real work of museums. Curator: the museum journal, 44(1), 8.

Cox-Petersen, A. M., Marsh, D. D., Kisiel, J., \& Melber, L. M. (2003). Investigation of guided school tours, student learning, and science reform recommendations at a museum of natural history. Journal of Research in Science Teaching, 4O(2), 200-218.

Coxall, H. (1999). Museum text as mediated message. In E. Hooper-Greenhill (Ed.), The Educational role of the museum (2nd ed., pp. XVI, 346). London: Routledge.

Cronbach, L. J. (1975). Beyond 2 Disciplines of Scientific Psychology. American Psychologist, 30(2), 116-127.

Csikszentmihalyi, M., \& Hermason, K. (1995). Intrinsic Motivation in Museums - What Makes Visitors Want to Learn. Museum News, 74(3), 34-79.

Dewey, J. (1938). Experience and education. New York,: The Macmillan company.

DeWitt, J., \& Hohenstein, J. (2010). School Trips and Classroom Lessons: An Investigation into Teacher-Student Talk in Two Settings. Journal of Research in Science Teaching, 47(4), 454-473.

DeWitt, J., \& Hohenstein, J. (2010,b). Supporting Student Learning: A Comparison of Student Discussion in Museums and Classrooms. Visitor Studies.

DeWitt, J., \& Osborne, J. (2007). Supporting teachers on science-focused school trips: Towards an integrated framework of theory and practice. International Journal of Science Education, 29(6), 685-710.

DeWitt, J., \& Osborne, J. (2010). Recollections of Exhibits: Stimulated-recall interviews with primary school children about science centre visits. International Journal of Science Education, 32(10), $1365-1388$.

DeWitt, J., \& Storksdieck, M. (2008). A Short Review of School Field Trips: Key Findings from the Past and Implications for the Future. Visitor Studies, 11(2), 16.

Dierking, L. D., Falk, J. H., Rennie, L., Anderson, D., \& Ellenbogen, K. (2003). Policy statement of the "informal science education" ad hoc committee. Journal of Research in Science Teaching, $40(2), 108-111$.

Dunn, R. (1984). Learning style: State of the science. Theory into practice, 23(1), 10.

Falcao, D., Colinvaux, D., Krapas, S., Querioz, G., Alves, F., Cazelli, S., Valente, M. E., \& Gouvea, G. (2004). A model-based approach to science exhibition evaluation: a case study in a Brazilian astronomy museum. International Journal of Science Education, 26(8), 951-978. 
Falk, J. H., \& Dierking, L. D. (2000). Learning from Museums: Visitor Experiences and the Making of Meaning: Altamira Press

Gardner, H. (2006). Multiple intelligences new horizons (Completely rev. and updated ed.). New York: BasicBooks.

Gilbert, J., \& Priest, M. (1997). Models and discourse: A primary school science class visit to a museum. Science Education, 81(6), 749-762.

Griffin, J. (1994). Learning to learn in informal science settings. Research in Science Education, 24(1), 8.

Griffin, J. (2004). Research on students and museums: Looking more closely at the students in school groups. Science Education, 88, S59-S70.

Griffin, J., \& Symington, D. (1997). Moving from task-oriented to learning-oriented strategies on school excursions to museums. Science Education, 81(6), 763-779.

Hein, G. E. (2002). Learning in the Museum. Routledge.

Heard, P. F., Divall, S. A., \& Johnson, S. D. (2000). Can 'ears-on' help hands-on science learning - for girls and boys? International Journal of Science Education, 22(11), 1133-1146.

Henriksen, E. K., \& Jorde, D. (2001). High school students' understanding of radiation and the environment: Can museums play a role? Science Education, 85(2), 189-206.

Hsi, S. (2003). A study of user experiences mediated by nomadic web content in a museum. Journal of Computer Assisted Learning, 19(3)

Hwang, G. J., Tsai, C. C., Chu, H. C., Kinshuk, \& Chen, C. Y. (2012). A context-aware ubiquitous learning approach to conducting scientific inquiry activities in a science park. Australasian Journal of Educational Technology, 28(5), 931-947.

Jarvis, T., \& Pell, A. (2005). Factors influencing elementary school children's attitudes toward science before, during, and after a visit to the UK National Space Centre. Journal of Research in Science Teaching, 42(1), 53-83.

Kisiel, J. F. (2003). Teachers, museums and worksheets: A closer look at a learning experience. Journal of Science Teacher Education, 14(1), 3-21.

Kisiel, J. F. (2005). Understanding elementary teacher motivations for science fieldtrips. Science Education, 89(6), 936-955.

Kisiel, J. F. (2007). Examining Teacher Choices for Science Museum Worksheets Journal of Science Teacher Education, 18, 29-43.

Lord, B. (2001). The purpose of museum exhibitions. In B. Lord (Ed.), The Manual of museum exhibitions (pp. XXV, 544 s.). Walnut Creek, Calif.: Alta Mira.

Metz, D. (2005). Field Based Learning in Science: Animating a Museum Experience. Teaching Education, 16(2), 18.

Miles, M. B., \& Huberman, A. M. (1994). Qualitative data analysis: an expanded sourcebook (2nd ed.). Thousand Oaks, Calif.: Sage.

Mortensen, M. F., \& Smart, K. (2007). Free-choice worksheets increase students' exposure to curriculum during museum visits. Journal of Research in Science Teaching, 44(9), 1389-1414.

Novak, J. D. (2002). Meaningful learning: The essential factor for conceptual change in limited or inappropriate propositional hierarchies leading to empowerment of learners. Science Education, 86(4), 548-571.

Pedretti, E. (2002). T. Kuhn meets T. Rex: Critical conversations and new directions in science centres and science museums. Studies in Science Education, 37(1), 41.

Rennie, L. I. (2007). Learning Science Outside of School. In S. K. Abell \& N. G. Lederman (Eds.), Handbook of research on science education (pp. XIV, 1330 s.). Mahwah, N.J.: Lawrence Erlbaum Associates.

Rennie, L. J. (1994). Measuring affective outcomes from a visit to a Science Education Centre. Research in Science Education, 24(1), 261-269.

Rennie, L. J., Feher, E., Dierking, L. D., \& Falk, J. H. (2003). Toward an agenda for advancing research on science learning in out-of-school settings. Journal of Research in Science Teaching, 4O(2), 112-12O. 
Rix, C., \& McSorley, J. (1999). An investigation into the role that school-based interactive science centres may play in the education of primary-aged children. International Journal of Science Education, 21(6), 577-593.

Rosenthal, E., \& Blankman-Hetrick, J. (2002). Conversations across time: Family learning in a living history museum. In K. Crowley, K. Knutson \& G. Leinhardt (Eds.), Learning conversations in museums (pp. XIII, 461 s.). Mahwah, N.J.: Lawrence Erlbaum.

Rounds, J. (2002). Storytelling in science exhibits. Exhibitionist, 21(2), 4.

Stavrova, O., \& Urhahne, D. (2010). Modification of a School Programme in the Deutsches Museum to Enhance Students' Attitudes and Understanding. International Journal of Science Education, 32(17), 2291-2310.

Stocklmayer, S., \& Gilbert, J. K. (2002). New experiences and old knowledge: towards a model for the personal awareness of science and technology. International Journal of Science Education, 24(8), 835-858.

Tal, R., Bamberger, Y., \& Morag, O. (2005). Guided school visits to natural history museums in Israel: Teachers' roles. Science Education, 89(6), 920-935.

Tal, T., \& Morag, O. (2007). School visits to natural history museums: Teaching or enriching? Journal of Research in Science Teaching, 44(5), 747-769.

Vygotsky, L. (1986). Thought and Language - Revised Edition (A. Kozulin Ed.): The MIT Press; revised edition edition.Yatani, K., Onuma, M., Sugimoto, M. \& Kusunoki, F. (2004). Musex: a system for supporting children's collaborative learning in a museum with PDAs Systems and Computers in Japan, 35(14), 54-63.

Yoon, S. A., Elinich, K., Wang, J., Steinmeier, C., \& Tucker, S. (2012). Using augmented reality and knowledge-building scaffolds to improve learning in a science museum. International Journal of Computer-Supported Collaborative Learning, 7(4), 519-541. 